\title{
Article \\ The Influence of Low-Temperature Disintegration on the Co-Fermentation Process of Distillation Residue and Waste-Activated Sludge
}

\author{
Anna Remiszewska-Skwarek ${ }^{1}$, Ryszard Wierzchnicki ${ }^{2}$, Otton K. Roubinek ${ }^{3}$, Archana Kasinath ${ }^{1}$, \\ Alicja Jeżewska ${ }^{1,4}$, Magdalena Jasinska ${ }^{5}$, Hubert Byliński ${ }^{1}{ }^{\mathbb{D}}$, Andrzej G. Chmielewski ${ }^{2}{ }^{\mathbb{D}}$ and \\ Krzysztof Czerwionka ${ }^{1, * \mathbb{D}}$
}

Citation: Remiszewska-Skwarek, A.; Wierzchnicki, R.; Roubinek, O.K.;

Kasinath, A.; Jeżewska, A.; Jasinska, M.; Byliński, H.; Chmielewski, A.G.; Czerwionka, K. The Influence of Low-Temperature Disintegration on the Co-Fermentation Process of Distillation Residue and Waste-Activated Sludge. Energies 2022, 15, 482. https://doi.org/ $10.3390 /$ en15020482

Academic Editor: Giorgio Vilardi

Received: 10 December 2021

Accepted: 7 January 2022

Published: 11 January 2022

Publisher's Note: MDPI stays neutral with regard to jurisdictional claims in published maps and institutional affiliations.

Copyright: (C) 2022 by the authors. Licensee MDPI, Basel, Switzerland. This article is an open access article distributed under the terms and conditions of the Creative Commons Attribution (CC BY) license (https:// creativecommons.org/licenses/by/ $4.0 /)$.
1 Faculty of Civil and Environmental Engineering, Gdansk University of Technology, 80-233 Gdansk, Poland; anna.skwarek@pg.edu.pl (A.R.-S.); archana.kasinath@pg.edu.pl (A.K.); ajezewska.gpk@chmielno.pl (A.J.); hubert.bylinski@pg.edu.pl (H.B.)

2 Institute of Nuclear Chemistry and Technology, 03-195 Warsaw, Poland; r.wierzchnicki@ichtj.waw.pl (R.W.); a.chmielewski@ichtj.waw.pl (A.G.C.)

3 Łukasiewicz-Industrial Chemistry Institute, Department of Pharmacy, Cosmetic Chemistry and Biotechnology, 01-793 Warsaw, Poland; otton.roubinek@ichp.lukasiewicz.gov.pl

4 Communal Municipal Company in Chmielno, 83-333 Chmielno, Poland

5 Faculty of Chemical and Process Engineering, Warsaw University of Technology, 00-661 Warsaw, Poland; magdalena.jasinska@pw.edu.pl

* Correspondence: kczer@pg.edu.pl

\begin{abstract}
Innovative low-temperature disintegration (process temperature $55^{\circ} \mathrm{C}$ and oxygen concentration $0.2 \mathrm{mg} / \mathrm{dm}^{3}$ ) can be an economically rational technology to intensifying energy production from renewable sources. The proposed process can achieve a degree of disintegration-under optimal conditions-of about $50 \%$, which is excellent when compared with other methods of feed pre-treatment. The low-temperature disintegration of distillation residue and waste-activated sludge before the co-fermentation process increased biogas production by $30 \%$ and methane production by $65 \%$ (over a $26 \mathrm{~d}$ duration). The obtained results confirm that the low-temperature disintegration method can be effectively used to pre-prepare this type of feed. At the same time, it was discovered that the Gompertz model can be used to mathematically describe the biogas accumulation curves in the methane co-fermentation processes of the tested feeds (the correlation coefficients were higher than 0.98).
\end{abstract}

Keywords: low-temperature disintegration; waste-activated sludge; distillation residue; co-digestion; Gompertz model

\section{Introduction}

In November 2018, the European Commission presented a long-term strategy for reducing greenhouse gas emissions, showing how Europe might lead the world along the path towards climate neutrality by creating a zero-greenhouse gas emissions economy [1] The vision of the European Commission comprises seven main strategic elements, including the maximization of energy efficiency, including the use of renewable energy sources (RES) to fully decarbonize energy supplies in Europe.

The development of renewable energy sources in Poland, despite many difficulties, has become a necessity due to the requirements of environmental protection related to high greenhouse gases emission in the power sector. The increase in demand for electricity and heat is related to the growing demand of the economy and the service sector. Satisfying these needs requires a disorganized structure of the so-called energy mix and is an incentive to work on the application of low-emission solutions, such as RES and nuclear energy [2]. 
The use of these energy sources will reduce the emission of gaseous pollutants, including those causing climate change and harming human health and the natural environment.

Highly effective methods of biological and chemical treatment aimed at increasing the removal of biogens and reducing organic matter generate significant amounts of sewage sludge (at an estimated amount of 2841.739 thousand tons in the European Union in 2018), which require management [3]. Therefore, looking for the new, economically rational and highly efficient solutions for sludge management is crucial and-bearing in mind that the costs of sludge treatment currently account for 50 to $70 \%$ of the operating budget of most wastewater treatment plants-even a cut of 1-2\% would offer measurable financial results (in millions of zlotys). Concurrently, striving to maximize the use of RES is one of the European Union's priorities for the next 30 years [1]. Therefore, solving problems related to the management of activated sludge (excess and primary) slots perfectly into the European Green Deal strategy and may constitute a significant contribution to the development of the RES economy, while the waste itself is a source (bioproduct/bio-waste) of highly efficient renewable energy [4]. Hence, the intensification of biogas production obtained as a result of fermentation of sewage sludge, whether as a result of disintegration or co-fermentation processes, and simultaneous biorefining, is an important branch of industry 4.0.

Several new agricultural biogas plants have been built in Poland in recent years, and this sector has the potential to grow due to the easy availability of raw materials and waste from the agri-food industry [5]. The Institute of Nuclear Chemistry and Technology has worked with partners to co-develop a modern biogas production plant. This solution uses the technology of anaerobic biomass processing carried out in two separate stages, hydrolysis and fermentation. This technology introduces a cascade system of tanks and equipment in the anaerobic fermentation system-i.e., hydrolyzers, fermenters, press or decanter centrifuge, and composter. Digestate, together with methane bacteria returned through the pipeline to the biomass preparation system and to the hydrolyser, accelerates the hydrolysis process and recycle the dry matter in suspension [6]. This installation uses a hydraulic system to simultaneously ensure transport of the suspension from the hydrolyser to the fermenter. The forced movement of the suspension is obtained by operating circulation pumps. Pumped slurry supplies the fermenter with a free stream falling on the surface of the liquid, breaking the root formed during the methane fermentation process. The geometry of the suspension flux discharge and supply system was developed on the basis of numerical simulations (CFD methods) to confirm the hydro-mixing efficiency of the fermentation suspension in fermenters. Computer simulation of nonsteady, three-dimensional fluid flow was performed using CFD. Visualization of velocity vectors, current lines, and trajectories of biomass suspension helped to model the mixing process and identify the structure, mixing, and dynamics (dead spaces, partial mixing, piston flow). Thanks to discretization and the numerical solution of partial differential equations describing the flow, it was possible to determine the distribution of velocity, pressure, temperature and other flow parameters [7]. Two agricultural biogas plants with a capacity of $1.2 \mathrm{MW}_{\mathrm{e}}$ each were built in Poland and supply electricity to the national grid.

In order to boost biogas production capabilities during the fermentation process, it is possible to pre-prepare the sludge (or another substrate that may constitute the fermentation input) using various methods. Disintegration is a process that causes destruction of structures within a flocculation of biological material (e.g., activated sludge) and disruption and lysis of microbial cells, via various methods. The most commonly applied methods are mechanical and ultrasound, and high-temperature (above $100^{\circ} \mathrm{C}$ ) thermal methods [8-10]. In recent years, low-temperature methods (below $100^{\circ} \mathrm{C}$ ) have also become more and more popular, whereby the energy input is much lower than in the case of high-temperature methods [11]. Low-temperature disintegration, despite lower energy consumption in relation to high-temperature disintegration, is not a commonly used process, as evidenced by the paucity of publications on the topic. Therefore, determining its impact on the intensification of biogas production, with simultaneous co-production, would significantly fill knowledge gaps, especially from the point of view of operators. 
A modified Gompertz model [12] was used to interpret and give meaningful description of the biogas accumulation curves. Due to its simplicity of description and good compatibility with experimental data, this model is often used to estimate the amount of biogas produced per dry weight unit. In addition to simplified models describing the production of biogas from a unit of dry matter or dry organic matter, the literature also offers more complex models such as ADM1 [13]. However, models of this type (including ADM1) require knowledge of many more parameters, and so the reliability of the former largely depends on the accuracy of the latter. In such a case, it is recommended to perform preliminary simulations determining the sensitivity of the influence of individual kinetic constants on the course of the tested and described process. However, the definite advantage of this class of models is a more complete description of the course of the methane fermentation process, considering most of the paths of changes, as well as the possibility of taking into account the balance of individual components in gas as well as liquid phases.

The study presented in this paper is related to upgrading the developed and implemented solution to be applied for biogas from the co-fermentation of mixed waste-surplus sludge from municipal wastewater treatment plants and waste of agricultural origin. Disintegration of such mixed waste plays a key role in equalization of the content and flocks size to assure bacteria access to biomass bulk. Preliminary preparation of substrates in agricultural biogas plants and municipal settings located at municipal wastewater treatment plants is aimed at increasing the efficiency of biogas production, which can be used in the cogeneration process to produce heat and electricity. In addition to the production of biogas, hygienized digestate obtained from excess sludge can be used as a valuable organic fertilizer [14]. Utilization of sludge from wastewater treatment plants, including surplus sludge and waste materials from the agri-food industry in the process of methane co-fermentation, may be a method that will boost the production of biogas from available resources of raw materials containing organic carbon

The low-temperature method for conditioning substrates in the co-fermentation process leads to enhanced methane production efficiency [15]. This paper compares the results of biogas production efficiency in the co-fermentation of a mixture of distillery decoction and excessive sludge subjected to preliminary conditioning by low-temperature disintegration with co-fermentation of the substrates themselves without their initial preparation. The method of low-temperature disintegration was developed at the Gdańsk University of Technology.

\section{Materials and Methods}

\subsection{Research Material}

Waste-activated sludge and digestate delivered from the municipal wastewater treatment plant in Warsaw were used for the research. The distillation residue came from a distillery located in southeastern Poland. The characteristics of the substrates are presented in Table 1. A mixture consisting of $20 \% w / w$ digestate (used as the inoculum) and $80 \% w / w$ stillage mixed with excess sludge in a ratio of 1:3 was used to feed the reactors. The proportion of stillage to excess sludge was determined based on preliminary laboratory tests.

Table 1. Characteristics of the substrates used in the research.

\begin{tabular}{ccc}
\hline Substrate & Total Solids (TS) [\% w/w] & Volatile Solids (VS) [\% $w / w]$ \\
\hline Inoculum & $2.0-2.8$ & $47-75$ \\
Waste-activated sludge & $0.5-3$ & $55-75$ \\
Distillation residue & $6-8$ & $81-95$ \\
\hline
\end{tabular}

During the research, two experiments labeled E1 and E2 were carried out in tandem using two identical reactors. The experiments differed only in terms of the initial preparation of the reactor feed (Table 2). The content of dry matter (TS) and organic dry matter $(\mathrm{VS})$ in the feed was established, and the carbon to nitrogen $(\mathrm{C} / \mathrm{N})$ ratio was determined. 
Table 2. Characteristics of the feed used in the research.

\begin{tabular}{ccccc}
\hline Experiment & Disintegration Method & $\begin{array}{c}\text { Total Solids (TS) } \\
{[\% w / w]}\end{array}$ & $\begin{array}{c}\text { Volatile Solids (VS) } \\
{[\% w / w]}\end{array}$ & C/N \\
\hline E1 & none & 5.5 & 64 & 9.3 \\
E2 & low-temperature & 5.3 & 61 & 7.8 \\
\hline
\end{tabular}

For the reference reactor (E1), initial feed hydrolysis was carried out at a temperature of approx. $30{ }^{\circ} \mathrm{C}$ during the first two days. The main process of methane fermentation was carried out at a temperature of about $38^{\circ} \mathrm{C}$. The initial $\mathrm{pH}$ in the fermenter was adjusted to 7.2-7.3 by adding $\mathrm{NaHCO}_{3}$.

\subsection{Low-Temperature Disintigration}

The process of low-temperature disintegration of the tested feed was carried out on a laboratory scale with the use of reactors with a total volume of $20 \mathrm{dm}^{3}$, equipped with a heat distribution system, an apparatus for inputting oxygen into the reactor, and mechanical stirrers. During each of the experiments, $15 \mathrm{dm}^{3}$ of feed was tested, with the following processing conditions:

- Processing temperature: 45 and $55{ }^{\circ} \mathrm{C}$;

- Feed retention time in the reactor: 24 and 48 h;

- Oxygen concentration in the reactor during the process: $0.2 \mathrm{mg} / \mathrm{dm}^{3}$;

- Mixing intensity: $25 \mathrm{~Hz}$.

The selection of conditions for the process was developed on the basis of previously conducted studies using feed with similar physicochemical characteristics and on information from the literature on the disintegration process for various substrates [16]. To the best of author's knowledge, a temperature range of $45-55^{\circ} \mathrm{C}$ and feed retention time can allow a beneficial solubilization degree to be obtained; dissolved oxygen concentration of $0.2 \mathrm{mg} / \mathrm{dm}^{3}$ ensures aerobic condition of process; mixing intensity of $25 \mathrm{~Hz}$ ensures distribution of oxygen as well as heat.

In order to determine the effectiveness of the low-temperature disintegration process, the tested feed was also subjected to a process of chemical disintegration. For this purpose, a $1 \mathrm{M} \mathrm{NaOH}$ solution was added to $500 \mathrm{~cm}^{3}$ of the tested feed and the whole batch was mixed by a mechanical stirrer for $24 \mathrm{~h}$.

\subsection{Laboratory Methane Fermentation System}

In research on the production of biogas from investigated substrates, horizontal cylindrical fermenters were used with diameter $d=0.305 \mathrm{~m}$ and length $1=0.60 \mathrm{~m}$. The volume of the fermenter was $V=44 \mathrm{dm}^{3}$. The volume of the initial suspension in the fermenter was $32 \mathrm{dm}^{3}$. The reactors were located on a rack and equipped with thermocouples to measure the temperature inside them. Thermostat systems installed in reactors were made of coils in tanks with Hubber thermocirculation statues connected to them. A diagram of the reactor is shown in Figure 1 and the photo in Figure 2.

To evaluate distribution the velocity of the suspension inside the fermenter during hydro mixing, simulations were carried out using Fluid Mechanics software (CFD simulation software Ansys Fluent). A diagram of the velocity distribution in the longitudinal section, containing the symmetry axis of the fermenter, for volume flow of the suspension $Q=30 \mathrm{dm}^{3} / \mathrm{min}$. and diameter of the inflow and outflow pipes $\mathrm{d}=2 \mathrm{~cm}$ are shown in Figure 3. The obtained results demonstrated the presence of circulation loops, proving the design assumption that hydromixing the liquid stream causes good mixing fermenter content [17].

During the experiments, samples of the suspension were collected from the fermenters 2-3 times per week, and gas samples were collected 5-6 times per week. The fermenter suspension samples were tested for TS and VS content. 


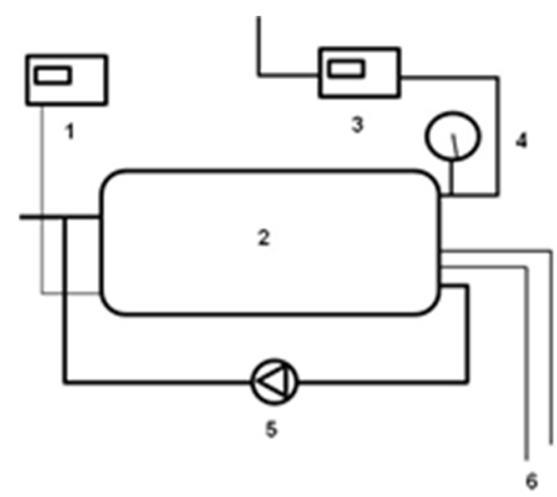

Figure 1. Scheme of a bioreactor: (1) temperature meter, (2) $44 \mathrm{dm}^{3}$ reactor, (3) gas quantity meter, (4) pressure gauge, (5) centrifugal pump, (6) liquid inflow and outflow from the recirculation thermostat.

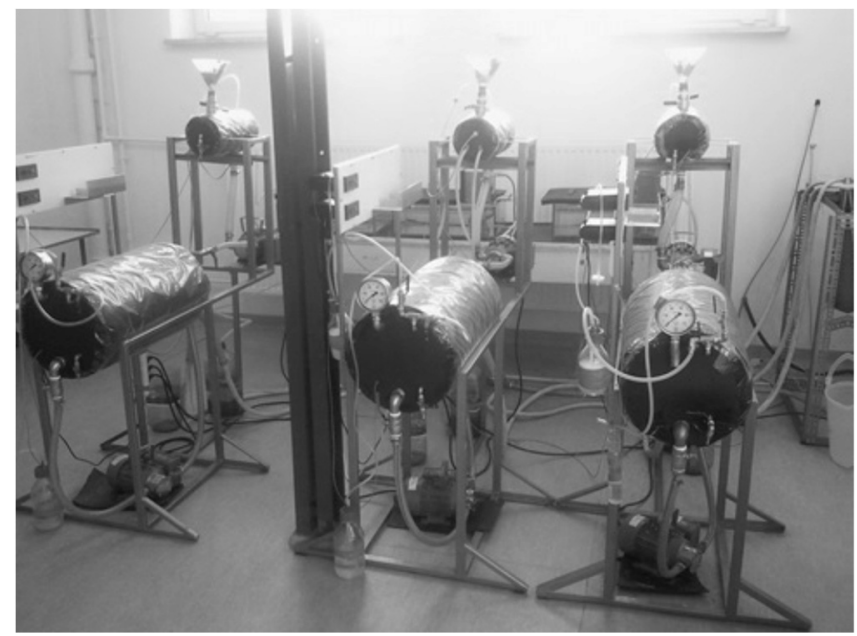

Figure 2. Reactors for carrying out research on the methane fermentation process.

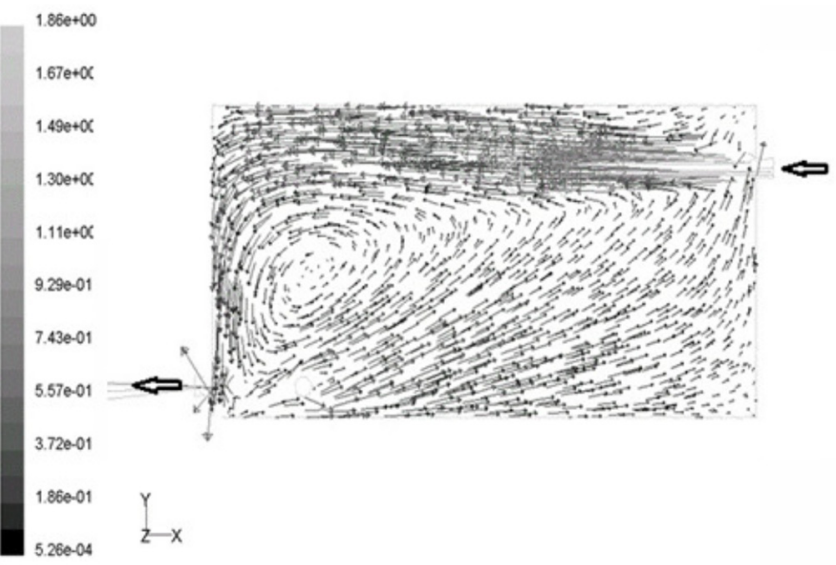

Figure 3. Velocity distribution in the longitudinal section containing axis of symmetry in the fermenter for volume flow $\mathrm{Q}=30 \mathrm{dm}^{3} / \mathrm{min}$. and diameter of the inlet/outlet pipes $\mathrm{d}=2.0 \mathrm{~cm}$.

\subsection{Analytical Methods}

TS and VS were measured according to the norms described in Standard Methods for Examination of Water and Wastewater [18]. The gas composition (in relation to $\mathrm{CH}_{4}, \mathrm{CO}_{2}$ ) was determined on an ongoing basis with a GeoTech GA5000 biogas analyzer. The amount of biogas was measured using a dedicated Ritter MCG 01 biogas meter. The $\mathrm{C} / \mathrm{N}$ ratio in TS was measured on a ThermoFinnigan Flash EA 1112NC Elementary Analyzer. The pH 
measurement was performed with a laboratory $\mathrm{pH}$ meter Elmetron $\mathrm{CX}-401$ in cooperation with a $\mathrm{pH}$ Elmetron Iodone IJ44A electrode.

For samples taken during the disintegration process, the following characteristic parameters were determined for the tested feed: $\mathrm{pH}$, conductivity, redox and dissolved oxygen concentration (analyses performed via a multi-functional HQ40D meter, Hach, Germany). In order to determine the characteristics of the dissolved phase, the feed samples were centrifuged (10,000 RPM, $30 \mathrm{~min})$ and filtered under reduced pressure (filters with a pore diameter of $0.45 \mu \mathrm{m}$ ). The resulting dissolved phase was subjected to spectrophotometric analyses to determine chemical oxygen demand (COD); concentrations of nitrates and nitrites $\left(\mathrm{NO}_{2}-\mathrm{N}, \mathrm{NO}_{3}-\mathrm{N}\right)$, ammonium, and total nitrogen $\left(\mathrm{NH}_{4}-\mathrm{N}, \mathrm{TN}\right)$; and concentrations of volatile fatty acids (VFA), phosphate phosphorus, and total phosphorus $\left(\mathrm{PO}_{4}-\mathrm{P}, \mathrm{TP}\right)$. During the disintegration process, changes in the concentrations of selected substances released during this process-ammonia, hydrogen sulfide, oxygen, methane, and carbon dioxide-were determined by using an analyzer of mixed gas composition (Biogas 5000 Gas Analyzer, Geotechnical Instruments, Ltd., Leamington Spa, UK).

The degree of disintegration for samples taken during the low-temperature disintegration process was determined based on COD and TCOD values (determined as COD for samples subjected to the chemical disintegration process), according to the following formula:

$$
\mathrm{DD}=\left[\mathrm{COD}_{\text {treated }}-\mathrm{COD}_{0} / \mathrm{TCOD}-\mathrm{COD}_{0}\right] \times 100 \%
$$

where:

DD—disintegration degree [\%];

$\mathrm{COD}_{\text {treated }}-\mathrm{COD}$ values for samples after low-thermal disintegration $\left[\mathrm{mg} / \mathrm{dm}^{3}\right]$;

$\mathrm{COD}_{0}-\mathrm{COD}$ values for untreated samples $\left[\mathrm{mg} / \mathrm{dm}^{3}\right]$;

TCOD—total COD values obtained from chemical disintegration $\left[\mathrm{mg} / \mathrm{dm}^{3}\right]$.

\subsection{Mathematical Modelling}

In order to describe mathematically the biogas accumulation curves generated in the methane co-fermentation processes, a modified Gompertz model was used, which is applied in the presence of sigmoid curves. This model was used to model the biogas accumulation curves obtained in the methane co-fermentation processes of fruit and vegetable waste with sugar cane bagasse [12]. The basic relationship used to describe the released biogas during the fermentation process can be represented by a modified logistic curve expressed in this case as:

$$
y(t)=a \exp [-\exp [(b e / a) \cdot(c-t)+1]]
$$

where:

$\mathrm{y}(\mathrm{t})$-biogas accumulation $\left[\mathrm{dm}^{3} / \mathrm{kg}\right.$ TS]

a-maximum value of biogas production $\left[\mathrm{dm}^{3} / \mathrm{kg} \mathrm{TS}\right]$

e-base of natural logarithm 2.718

$\mathrm{b}$-biogas production rate $\left[\mathrm{dm}^{3} / \mathrm{kg}\right.$ TS d]

c-incubation phase [d]

$\mathrm{t}$ - experiment time $[\mathrm{d}]$

The quantity of biogas accumulation is calculated on the basis of three parameters and the duration of the methane fermentation process. Maximum biogas production means the amount of biogas that can be produced per dry weight unit. The rate of biogas production is described by rate constant of first order, and the adaptation phase refers to the time needed for microorganisms to multiply in the fermenter after inoculation preceding the logarithmic growth phase.

\section{Results and Discussion}

\subsection{Low-Temperature Disintegration Efficiency}

The effectiveness of the low-temperature disintegration process for the tested feed may be determined on the basis of results obtained during analysis. The characteristics 
of the sludge and the dissolved phase obtained in the sludge samples before and after the disintegration process are presented in Table 3. Following an analysis of the obtained results, some changes may be demonstrated in the composition of the tested substrate that are of particular relevance to this process. The $\mathrm{pH}$ values presented in Table 3 drop slightly during the disintegration process, but it is worth noting that regardless of the process conditions, the $\mathrm{pH}$ value always remains above 6.0, which may indicate good process stability. A similar conclusion may be drawn following an analysis of the values of dissolved oxygen concentrations obtained and the redox potential. The $\mathrm{O}_{2}$ concentration ranges from $0.1-0.4 \mathrm{mg} / \mathrm{dm}^{3}$, yet the redox potential always remains positive, which proves good oxygen availability for the tested substrate, which is vital from the point of view of maximizing the decomposition of the tested biomass.

Table 3. Physical and chemical characteristics of the dissolved phase of the initial feed and after being subjected to the low-temperature disintegration process.

\begin{tabular}{cccccc}
\hline Temperature $\left({ }^{\circ} \mathbf{C}\right)$ & \multirow{2}{*}{ Raw Sample } & \multicolumn{2}{c}{$\mathbf{4 5}{ }^{\circ} \mathbf{C}$} & \multicolumn{2}{c}{$\mathbf{5 5}{ }^{\circ} \mathbf{C}$} \\
\cline { 5 - 6 } Feed Retention Time (h) & & $\mathbf{2 4} \mathbf{h}$ & $\mathbf{4 8} \mathbf{h}$ & $\mathbf{2 4} \mathbf{~ h}$ & $\mathbf{4 8 ~ h}$ \\
\hline $\mathrm{pH}(/)$ & 6.8 & 6.6 & 6.4 & 6.2 & 6.1 \\
Redox $(\mathrm{mV})$ & 106.3 & 62.4 & 38.2 & 51.6 & 33.1 \\
Conductivity $(\mathrm{mS} / \mathrm{cm})$ & 10.6 & 11.1 & 15.6 & 11.2 & 17.2 \\
$\mathrm{DO}\left(\mathrm{mg} / \mathrm{dm}^{3}\right)$ & 0.4 & 0.2 & 0.2 & 0.1 & 0.2 \\
$\mathrm{COD}\left(\mathrm{mg} / \mathrm{dm}^{3}\right)$ & 22,905 & 34,589 & 38,223 & 42,331 & 49,885 \\
$\mathrm{LKT}\left(\mathrm{mg} / \mathrm{dm}^{3}\right)$ & 4902 & 9020 & 12,389 & 11,090 & 15,223 \\
$\mathrm{PO}_{4}-\mathrm{P}\left(\mathrm{mg} / \mathrm{dm}^{3}\right)$ & 19.1 & 44.5 & 51.3 & 55.7 & 75.9 \\
$\mathrm{TP}\left(\mathrm{mg} / \mathrm{dm}^{3}\right)$ & 22.0 & 48.2 & 57.8 & 61.2 & 82.0 \\
$\mathrm{NO}_{2}-\mathrm{N}\left(\mathrm{mg} / \mathrm{dm}^{3}\right)$ & 9.2 & 11.2 & 15.3 & 21.2 & 24.3 \\
$\mathrm{NO}_{3}-\mathrm{N}\left(\mathrm{mg} / \mathrm{dm}^{3}\right)$ & 45.0 & 101.2 & 134.0 & 145.2 & 180.2 \\
$\mathrm{NH}_{4}-\mathrm{N}\left(\mathrm{mg} / \mathrm{dm}^{3}\right)$ & 143.2 & 211.0 & 254.6 & 344.6 & 455.6 \\
$\mathrm{TN}\left(\mathrm{mg} / \mathrm{dm}^{3}\right)$ & 233.2 & 334.2 & 445.3 & 773.2 & 920.1 \\
\hline
\end{tabular}

Considering the parameters illustrating the rate of organic matter decomposition during the disintegration process, special attention should be paid to the COD and VFA values obtained for samples subjected to the low-temperature disintegration process. Based on the data collected in Table 3, it can be concluded that in the case of the conducted research, the values of these two parameters are much higher for the thermally processed feed. When the process was carried out at $55^{\circ} \mathrm{C}$ with a retention time of $48 \mathrm{~h}$, a nearly twofold increase in COD concentrations and an over three-fold increase in VFA concentrations was noted with respect to the values of these parameters obtained for the non-integrated charge. Conducting the process in such conditions yields the highest values, and so the process of matter decomposition is highly intensive.

During the disintegration process, a sharp rise in the release of various forms of compounds containing nitrogen and phosphorus was also observed, as detailed in Table 3. The decomposition of complex compounds into simpler forms is also associated with an increase in conductivity, which results from the growth in the number of ionized forms dissociating in aqueous solutions and capable of transferring electric charges.

Based on the COD values obtained while testing, after the process of low-temperature disintegration and chemical disintegration, it was possible to determine the degree of disintegration (DD); the results are presented in Figure 4. Based on these outcomes, it can be concluded that a peak value of $52.39 \%$ was obtained for $48 \mathrm{~h}$ of feed retention time in the reactor at a temperature of $55^{\circ} \mathrm{C}$. Conducting the process at $45{ }^{\circ} \mathrm{C}$ makes it possible to obtain a DD of $37.72 \%$, while a retention time of $24 \mathrm{~h}$, regardless of the temperature, yields DD values below $30 \%$. Therefore, when interpreting the results obtained, it should be stated that in the case of the tested substrate, it is recommended to conduct the process at a temperature of $55^{\circ} \mathrm{C}$, maintaining the sludge retention time in the reactor at $48 \mathrm{~h}$. 


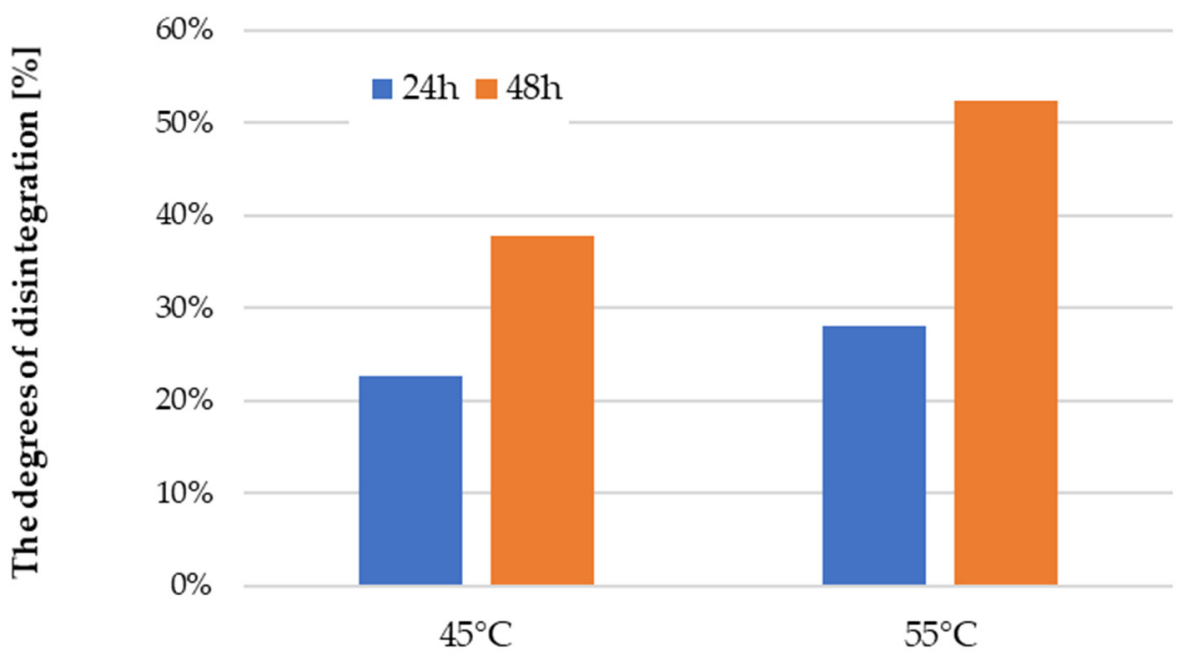

Figure 4. The degrees of disintegration (DD) obtained for various process conditions.

Table 4 summarizes the concentrations of the main components of the gas released during the low-temperature disintegration process. Two compounds-hydrogen sulfide and ammonia-deserve particular attention. The concentrations of these two substances are definitely higher for the process carried out at $55{ }^{\circ} \mathrm{C}$ (for both feed retention times of $24 \mathrm{~h}$ and $48 \mathrm{~h}$ ). Hydrogen sulfide is commonly considered to pose a strong odorous nuisance due to its very low odor threshold concentration. Therefore, even at very low concentration levels, it can significantly increase the degree of odor nuisance related to, inter alia, the processing of sewage sludge. Ammonia is another one of the most onerous odorants that, when present in the reaction gas, present a challenge in terms how to purify the gas and eliminate the emission of these compounds.

Table 4. Reaction gas parameters measured during the low-temperature disintegration process for the tested feed.

\begin{tabular}{ccccc}
\hline \multirow{2}{*}{ Main Components of the Gas } & \multicolumn{2}{c}{$\mathbf{4 5}{ }^{\circ} \mathbf{C}$} & \multicolumn{2}{c}{$\mathbf{5 5}{ }^{\circ} \mathbf{C}$} \\
\cline { 2 - 5 } & $\mathbf{2 4} \mathbf{h}$ & $\mathbf{4 8 ~ h}$ & $\mathbf{2 4} \mathbf{~ h}$ & $\mathbf{4 8 ~ h}$ \\
\hline $\mathrm{CH}_{4}[\%]$ & 0.2 & 0.3 & 0.3 & 0.4 \\
$\mathrm{CO}_{2}[\%]$ & 0.2 & 0.2 & 0.8 & 0.7 \\
$\mathrm{O}_{2}[\%]$ & 19.8 & 19.9 & 19.7 & 19.7 \\
$\mathrm{NH}_{3}[\mathrm{ppm}]$ & 4.9 & 5.0 & 27.0 & 38.4 \\
$\mathrm{H}_{2} \mathrm{~S}[\mathrm{ppm}]$ & 4.2 & 7.0 & 32.0 & 47.1 \\
\hline
\end{tabular}

The results presented in this paper make it possible to assess the effectiveness of the low-temperature disintegration process for the tested feed, which is a mixture of wasteactivated sludge and distillation residue. VFA and COD are certainly relevant indicators for the degree of decomposition of the tested biomass and the degree of disintegration. Regardless of the process temperature set or the feed retention time in the reactor, an over $50 \%$ increase in VFA or COD is obtained compared to a non-disintegrated test. In the literature, such values are considered extremely favorable and often difficult to achieve in less than $24 \mathrm{~h}$. The literature presents a significant number of examples that tend to refer to the efficiency of disintegration of excess sludge only. However, in one study [19], the effectiveness of this process was compared for higher temperatures $\left(70,80\right.$, and $\left.90^{\circ} \mathrm{C}\right)$ and within a much shorter duration $(15,30$, and $60 \mathrm{~min})$. In this case, the authors indicate that such a short time makes a temperature of $70{ }^{\circ} \mathrm{C}$ relatively ineffective for achieving a highly efficient decomposition of complex compounds; for example, the disintegration level determined for this temperature was only $1.36 \%$ for a $24 \mathrm{~h}$ retention time. In the case of the tests described in this paper, it was necessary to extend the time to a minimum of 
$24 \mathrm{~h}$, while using a much higher process temperature $\left(90^{\circ} \mathrm{C}\right)$ to obtain a disintegration level of $17.81 \%$, which is still relatively low compared to the values obtained in this study. From an economic standpoint, it is extremely relevant to find the optimum in terms of the substrate retention time in the reactor, while reducing the energy consumption needed to heat the substrate to higher temperatures, not only on a laboratory scale but, above all, on a technical scale. Moreover, low-temperature disintegration executed at a temperature of $90{ }^{\circ} \mathrm{C}$ yields a relatively large amount of water that converts into steam, hence the necessity to condense the vapors and return them to the reactor-e.g., by using a cooler.

It is also worth paying attention to the level of disintegration, which illustrates the potential of the proposed solution in the terms of pre-treating the tested feed. During the research presented in this paper, this ranged (depending on the process conditions) from about 20 to about $50 \%$. Studies are often cited in the literature in which the authors obtained much lower levels (approx. 15-25\%), both for heat treatment and with the use of other disintegration methods $[11,20,21]$.

Therefore, referring to the examples from the literature, one might conclude that the proposed solution for pre-treating the tested feed can achieve effective decomposition of complex compounds into simpler forms, easier to decompose further during methane fermentation. The proposed technology offers a much better use of waste, such as sewage sludge, and raw materials such as stillage, whose addition to the sludge using the presented method of treatment does not damage the process. In order to maximize the benefits of the presented method, the release of odorous substances should be taken into consideration because, due to the low threshold values of odor perceptibility, they may prove onerous (notwithstanding their harmful impact on human health) [22]. The levels of ammonia and hydrogen sulfide concentrations obtained during the process carried out at $55{ }^{\circ} \mathrm{C}$ are much higher than at $45^{\circ} \mathrm{C}$. When analyzing the threshold values of these compounds, the concentrations obtained for the higher of the two temperatures are relatively high, and when implementing the proposed technology, it will also be necessary to introduce technology to reduce emission to the environment. These compounds are commonly known odorants, and there are many methods outlined in the literature on how to neutralize their negative environmental impact $[23,24]$. Unfortunately, biomass pre-treatments are still insufficiently researched to determine their effectiveness levels with simultaneous evaluations of the odor properties of biogas streams. For this reason, there is a need to carry out further research in order to determine the relationship between the strength of the odor released and the chemical composition of odor mixtures. On the other hand, taking into account the obtained test results holistically, it can be concluded that conducting a low-temperature disintegration process for the tested feed may help achieve satisfactory levels. Despite longer residence time and higher reactor volume, low-thermal disintegration in comparison to substrate pre-treatment at higher temperature can allow good solubilization of biomass to be obtained. Longer duration time can have positive impact on rheological properties of the substrate before anerobic digestion. As a consequence, biosolids can have better quality in terms of odor emission.

\subsection{Production and Composition of Biogas}

The low-temperature disintegration method for pre-preparing the feed, which included waste-activated sludge and distillation residue, boosted the amount of biogas produced along with its methane content. It was discovered that the production of biogas increased by $30 \%$ and methane by $65 \%$ (Table 5). At the same time, the rate of biogas production increased by $36 \%$ in relation to the co-fermentation of the feed without pre-preparation. The test results are presented in Figure 5 with biogas and methane accumulation curves.

Table 5. Accumulation of biogas and methane over a 25-day fermentation process.

\begin{tabular}{cccc}
\hline Experiment & Biogas $\left[\mathbf{d m}^{3} / \mathbf{k g ~ V S}\right]$ & Methane $\left[\mathbf{d m}^{3} / \mathbf{k g ~ V S}\right]$ & Methane $[\%$ v/v] \\
\hline E1 & 295.3 & 153.4 & 53.6 \\
E2 & 384.0 & 253.8 & 66.1 \\
\hline
\end{tabular}




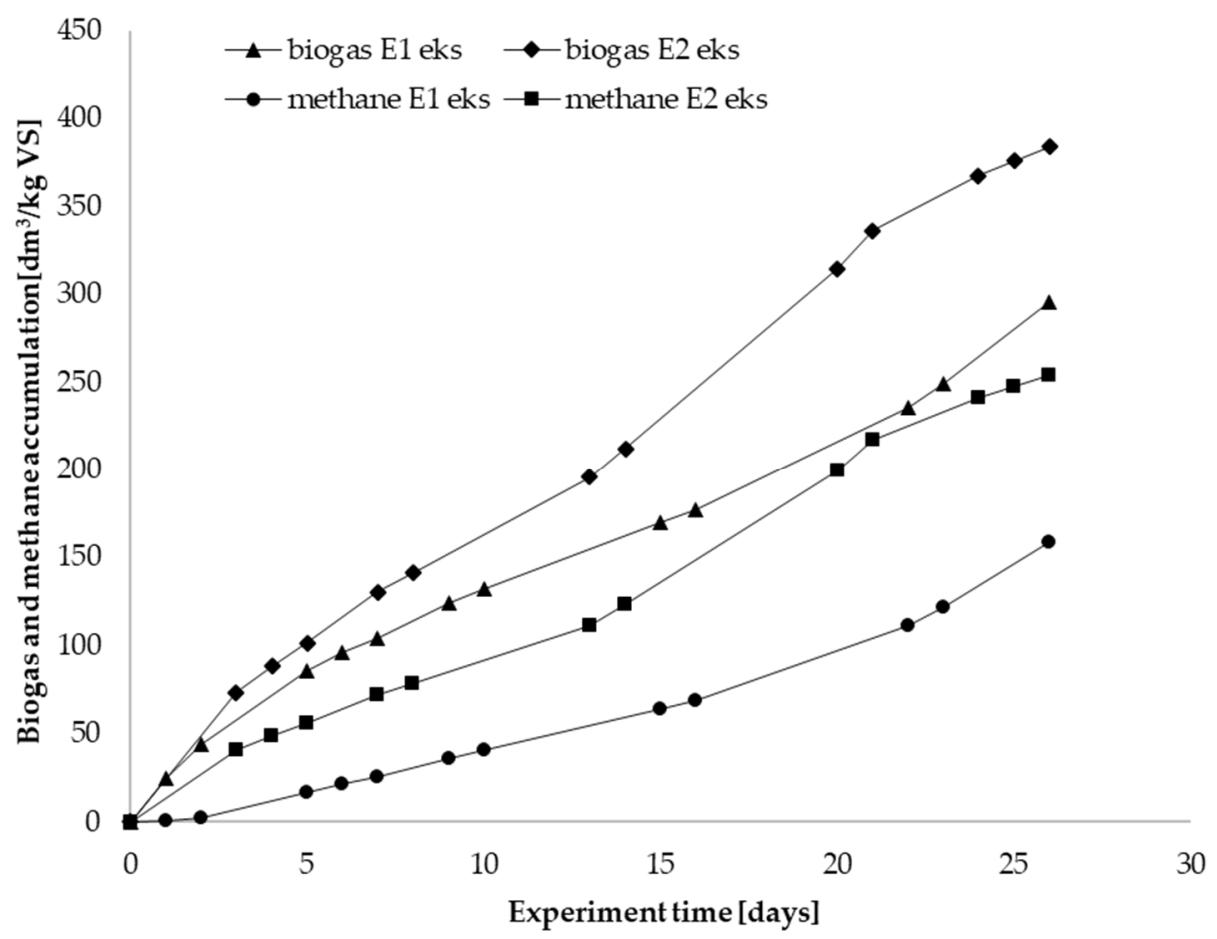

Figure 5. Biogas and methane accumulation curves for experiments E1 and E2.

The conducted study may be compared with the research presented by Garlicka et al. [25] made in identical bioreactors. Here, waste-activated sludge was used without superelectronization, but the excess sludge was fed by hydrodynamic disintegration, during which a cavitation effect occurred. As a result of this research, a 37\% increase in the amount of biogas production was obtained, while methane was up by $152 \%$ per VS unit at an optimal energy density equal to $140 \mathrm{KJ} / \mathrm{dm}^{3}$ [25]. This leads to the conclusion that the application of the hydrodynamic and low-temperature disintegration method boosts the amount of biogas and methane for waste-activated sludge. The effect of supplementation on excess sludge has not been investigated, nor have the two methods been compared. Both methods require mechanical or thermal energy supply, which may affect their profitability.

Most research on the methane fermentation process tends to be performed in small volumes ranging from $0.1-2 \mathrm{dm}^{3}$, due to applying the methane fermentation test procedure developed by Angelidaki et al. [26]. The research presented in this article was conducted on a much larger volume of tens of liters. Therefore, compared to standard studies, the scale of this research was about 10 times larger. In the case of the co-fermentation of wheat straw (WS) with the addition of sunflower meal (SM), a 61\% increase in biogas was observed. While applying the initial feed processing with the use of the high-temperature method (HT), the best result was obtained at a temperature of $180{ }^{\circ} \mathrm{C}$. However, these studies were conducted in $300 \mathrm{~cm}^{3}$ bottles. The use of supplementation and the HT method increased the amount of biogas produced by $94 \%$ [27].

The influence of low-temperature disintegration on feed subjected to co-fermentation in the presented study may be assessed on the basis of the data appearing in Table 2. The values of TS and VS for experiment E2 are not significantly lower than those for experiment E1. This indicates a slight loss in terms of dry matter and organic matter. At the same time, a decrease in the $\mathrm{C} / \mathrm{N}$ ratio of 9.3 to 7.8 was discovered, which proves a decrease in the organic carbon content in the liquid after feed disintegration. The data on VFA and COD (Table 3 ) in the liquid before and after disintegration at $55^{\circ} \mathrm{C}$ confirm the increased presence of organic carbon in the sample after disintegration. The increase in COD is $117.5 \%$ and the increase in VFA is $210.5 \%$.

The literature includes the results of tests conducted on various types of feed in order to obtain the best biogas efficiency per kilogram of substrate dry matter. Very often, these 
studies have focused on the composition of two or three substrates (referred to as the cofermentation process). At present, mixes are often sought that enable the elimination of one of the components whose disposal poses a serious problem due to applicable regulations. For this purpose, co-fermentation of sewage sludge and with a certain group of waste is used in order to protect the natural environment and close the waste management cycle. Articles published on this subject present research on various feeds (Table 6) at various scales, from laboratory to semi-technical.

Table 6. Methane co-fermentation of sludge from wastewater treatment plants with wastes from various industries and trades [28,29].

\begin{tabular}{cccc}
\hline Sludge Type & Co-Substrate & Ratio & $\begin{array}{c}\text { Methane } \\
{\left[\mathbf{m}^{3} / \mathbf{k g} \text { VS }\right]}\end{array}$ \\
\hline & Food wastes & $60 / 40(\mathrm{VS} / \mathrm{VS})$ & $0.18-0.33$ \\
Mixed sludge & Waste grease & $40 / 60(\mathrm{VS} / \mathrm{VS})$ & 0.49 \\
& Hydrolyzed pulp & $48 / 52(\mathrm{VS} / \mathrm{VS})$ & 0.55 \\
& Glycerol & $99 / 1$ & $0.36-0.54$ \\
& Fruit and vegetable waste & $77 / 23(\mathrm{VS} / \mathrm{VS})$ & 0.78 \\
& Waste oils & $92 / 18$ & 0.86 \\
& & $94 / 6(\mathrm{VS} / \mathrm{VS})$ & 0.57 \\
& Slaughter waste & $95 / 5$ & 0.63 \\
\hline Waste-activated sludge & Organic fraction of municipal & $84 / 16(\mathrm{VS} / \mathrm{VS})$ & 0.62 \\
& waste & $59 / 41(\mathrm{VS} / \mathrm{VS})$ & 0.43 \\
& Bio-waste & $50 / 50$ & 0.17 \\
& Distillation & $75 / 25$ & 0.42 \\
& residue (this study) & & 0.254 \\
\hline
\end{tabular}

\subsection{Kinetics of the Co-Fermentation Process}

The estimation of the model parameters, simulation of the unit biogas production and the $r^{2}$ correlation coefficient are summarized in Table 7 and Figure 6 . In the mathematical description of the process, the model parameters were estimated here using the multiparameter optimization method in a data range from 0 to $25 \mathrm{~d}$. The calculations were made using our own procedure, written in the SCILAB environment. Based on the value of the " $r$ " correlation coefficients, it can be concluded that the model curves present a very good fit with the experimental data. The good accuracy of the fit in terms of the experiments conducted also enables the extrapolation of data and, consequently, further analysis of the fermentation process based on the course of the extrapolated curves. The estimation results are presented in the figure and the parameters in the equation are presented in Table 7.

The simulation results using a simplified approach (Gompertz model) are presented in Figure 7 in the form of biogas accumulation curves for experiments E1 and E2.

As previously mentioned, the Gompertz model simulation performed in this study made it possible to predict biogas production over a longer period, without the need to perform costly and time-consuming experiments. The results of the prediction are shown in Figure 7. In this case, it is clearly possible to determine the saturation state-i.e., the maximum possible production of biogas from a biomass unit. Depending on the method of process implementation (E1 or E2), these values differ slightly for a given moment in time. Further simulations for $\mathrm{t}>60 \mathrm{~d}$ would help determine the duration of methane fermentation for the maximum production of biogas from the same unit amount of carbon substrate, which will evidently be influenced by how the process is carried out.

In the case of the pre-treatment of the feed including WS with SM using the hightemperature method, the best result was obtained at a temperature of $180{ }^{\circ} \mathrm{C}$, and the amount of biogas production increased by $94 \%$. A modified Gompertz model was used to describe the biogas accumulation curves mathematically. This demonstrated that supplementation of the basic substrate and the use of HT disintegration resulted in a $22.5 \%$ 
increase in the maximum production volume, while the biogas production rate grew by $0.8 \%$. The results present a very good fit with the model $-\mathrm{r}^{2}=0.9980$ (in the case of supplementation), $\mathrm{r}^{2}=0.9860$ (in the case of supplementation and disintegration) [27].

Table 7. The estimated model parameters and unit simulation of biogas accumulation for 60 days.

\begin{tabular}{|c|c|c|c|c|}
\hline Experiment & $\mathrm{a}\left(\mathrm{dm}^{3} / \mathrm{kg} \mathrm{VS}\right)$ & $\mathrm{b}\left(\mathrm{dm}^{3} / \mathrm{kg} \mathrm{VS} \mathrm{d}\right)$ & $c(d)$ & $\mathrm{r}^{2}$ \\
\hline E1 & 748.2 & 11.0 & 0.0 & 0.9851 \\
\hline E2 & 596.8 & 15.7 & 0.0 & 0.9900 \\
\hline
\end{tabular}

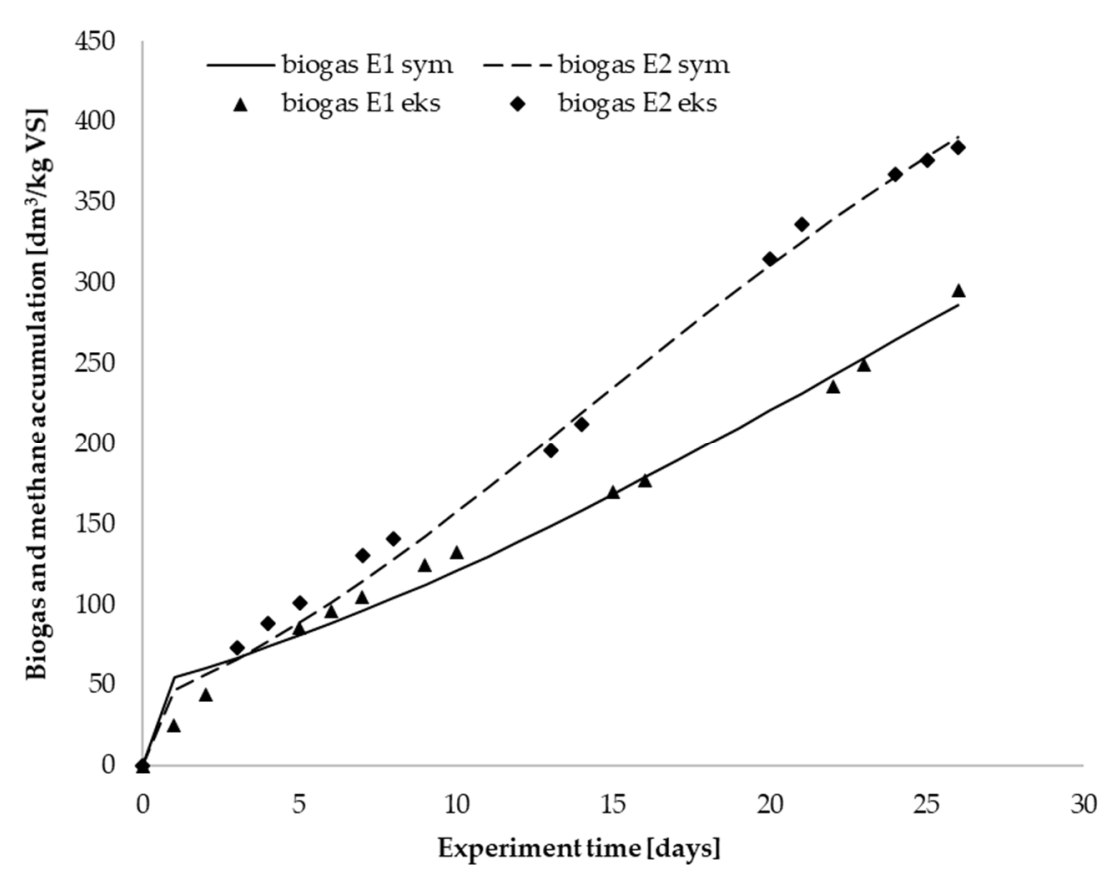

Figure 6. Biogas and methane accumulation curves for simulations and experiments E1 and E2.

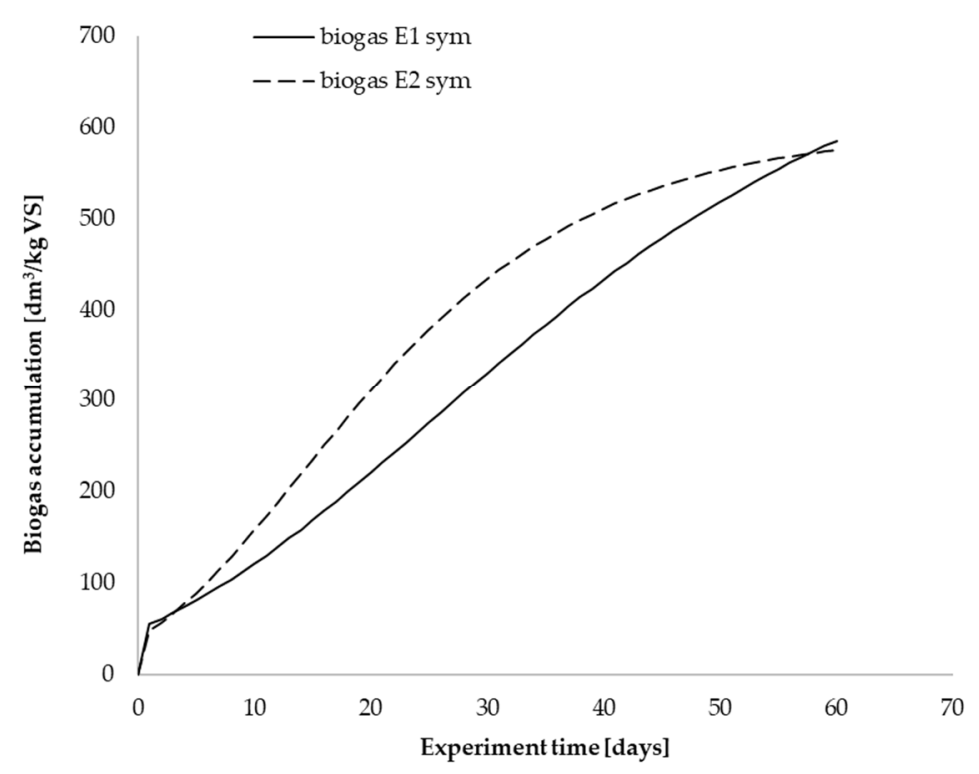

Figure 7. Simulation curves of biogas accumulation for E1 and E2.

\section{Conclusions}

The proposed innovative and at the same time economically rational technology of low-temperature disintegration, including sludge management, along with the possibility 
of using other substrates of agricultural origin, means that sewage sludge may be treated as a product rather than waste, thereby implementing the so-called circular economy model. At the same time, by intensifying energy production from renewable sources, the proposed technology falls in line with the global trend of so-called "green technology" as well as the international research area involving resource recovery. The results of the research carried out and described in this paper prove the sound efficiency of low-temperature disintegration technology. The proposed methodological solution can achieve a degree of disintegration-under optimal conditions-of about $50 \%$, which is excellent when compared with other methods of feed pre-treatment.

The disintegration of distillation residue and waste-activated sludge via the lowtemperature method before starting the methane co-fermentation process increased biogas production by $30 \%$, methane production by $65 \%$, and biogas production by $36 \%$ (over a $26 \mathrm{~d}$ duration). The obtained results confirm that the low-temperature disintegration method can be effectively used to pre-prepare this type of feed (distillation residue and waste-activated sludge in a proportion of 1:3). At the same time, it was discovered that the Gompertz model can be used to mathematically describe the biogas accumulation curves in the methane co-fermentation processes of the tested feeds. The values of the correlation coefficients for the performed experiments were, respectively, $\mathrm{r}^{2}=0.9851$ (E1) and $\mathrm{r}^{2}=0.9900(\mathrm{E} 2)$, which indicate a very strong correlation of the variables.

Author Contributions: Conceptualization, A.R.-S. and K.C.; methodology, O.K.R., R.W. and A.K.; visualization, R.W., A.J. and H.B.; formal analysis and data curation, A.G.C. and K.C.; investigation, R.W., O.K.R., A.K. and A.J.; writing-original draft preparation, O.K.R., M.J., A.R.-S., K.C. and H.B.; writing-review and editing, A.G.C. and K.C.; project administration and funding acquisition, K.C. All authors have read and agreed to the published version of the manuscript.

Funding: This study was financially supported by European Regional Development Fund within the framework of Smart Growth Operational Programme 2014-2020 under the project no POIR.04.01.0200-0022/17.

Data Availability Statement: Not applicable.

Conflicts of Interest: The authors declare no conflict of interest.

\section{References}

1. The European Commission. Communication from the Commission to the European Parliament, the European Council, the Council, the European Economic and Social Committee, the Committee of the Regions and the European Investment Bank. A Clean Planet for All a European Strategic Long-Term Vision for a Prosperous, Modern, Competitive and Climate Neutral Economy; European Commission: Brussels, Belgium, 2018.

2. Chmielewski, A.G. Energetyka jądrowa, dlaczego nie Polska? Instal 2019, 1, 11-16. (In Polish)

3. Eurostat-Sewage Sludge Production and Disposal. 2021. Available online: http://appsso.eurostat.ec.europa.eu/nui/show.do? lang=en\&dataset=env_ww_spd (accessed on 2 December 2021).

4. The European Commission. Communication from the Commission to the European Parliament, the Council, the European Economic and Social Committee and the Committee of the Regions European Climate Pact; European Commission: Brussels, Belgium, 2020.

5. Igliński, B.; Buczkowski, R.; Iglińska, A.; Cichosz, M.; Piechota, G.; Kujawski, W. Agricultural biogas plants in Poland: Investment process, economical and environmental aspects, biogas potential. Renew. Sustain. Energy Rev. 2012, 16, 4890-4900. [CrossRef]

6. Chmielewski, A.G.; Urbaniak, A.; Wawryniuk, K. Membrane enrichment of biogas from two-stage pilot plant using agricultural waste as a substrate. Biomass Bioenergy 2013, 58, 219-228. [CrossRef]

7. Chmielewski, A.G.; Berbeć, A.; Zalewski, M.; Dobrowolski, A. Hydraulic mixing modelling in reactor for biogas production. Chem. Process Eng. 2012, 33, 621-628. [CrossRef]

8. Camacho, P.; Deleris, S.; Geaugey, V.; Ginestet, P.; Paul, E. A comparative study between mechanical, thermal and oxidative disintegration techniques of waste activated sludge. Water Sci. Technol. 2002, 46, 79-87. [CrossRef]

9. Climent, M.; Ferrer, I.; Baeza, M.D.M.; Artola, A.; Vázquez, F.; Font, X. Effects of thermal and mechanical pretreatments of secondary sludge on biogas production under thermophilic conditions. Chem. Eng. J. 2007, 133, 335-342. [CrossRef]

10. Ennouri, H.; Miladi, B.; Diaz, S.Z.; Güelfo, L.A.F.; Solera, R.; Hamdi, M.; Bouallagui, H. Effect of thermal pretreatment on the biogas production and microbial communities balance during anaerobic digestion of urban and industrial waste activated sludge. Bioresour. Technol. 2016, 214, 184-191. [CrossRef] 
11. Ruffino, B.; Campo, G.; Genon, G.; Lorenzi, E.; Novarino, D.; Scibilia, G.; Zanetti, M. Improvement of anaerobic digestion of sewage sludge in a wastewater treatment plant by means of mechanical and thermal pre-treatments: Performance, energy and economical assessment. Bioresour. Technol. 2015, 175, 298-308. [CrossRef]

12. Vats, N.; Khan, A.A.; Ahmad, K. Effect of substrate ratio on biogas yield of anaerobic co-digestion of fruit vegetable \& sugar-cane bagasse. Environ. Technol. Innov. 2019, 13, 331-339. [CrossRef]

13. Batstone, D.J.; Keller, J.; Angelidaki, I.; Kalyuzhnyi, S.V.; Pavlostathis, S.G.; Rozzi, A.; Sanders, W.T.; Siegrist, H.A.; Vavilin, V.A. The IWA Anaerobic Digestion Model No. 1 (ADM1). Water Sci. Technol. 2002, 45, 65-73. [CrossRef]

14. Chmielewski, A.G.; Sudlitz, M. 'Zero energy' electron beam technology for sludge hygienization. Nukleonika 2019, 64, 55-63. [CrossRef]

15. Yan, Y.; Chen, H.; Xu, W.; He, Q.; Zhou, Q. Enhancement of biochemical methane potential from excess sludge with low organic content by mild thermal pretreatment. Biochem. Eng. J. 2013, 70, 127-134. [CrossRef]

16. Kasinath, A.; Fudala-Ksiazek, S.; Szopinska, M.; Bylinski, H.; Artichowicz, W.; Remiszewska-Skwarek, A.; Luczkiewicz, A. Biomass in biogas production: Pretreatment and codigestion. Renew. Sustain. Energy Rev. 2021, 150, 111509. [CrossRef]

17. Palige, J.; Roubinek, O.; Ciekowska, M.; Pyzik, A.; Dobrowolski, A.; Chmielewski, A.G. Badania wytwarzania biogazu z kiszonki kukurydzy w reaktorze okresowym z hydromieszaniem. Inżynieria I Apar. Chem. 2016, 55, 32-33.

18. APHA. Standard Methods for the Examination of Water and Wastewater, 21st ed.; American Public Health Association: Washington, DC, USA, 2005.

19. Appels, L.; Degrève, J.; Van der Bruggen, B.; Van Impe, J.; Dewil, R. Influence of low temperature thermal pre-treatment on sludge solubilisation, heavy metal release and anaerobic digestion. Bioresour. Technol. 2010, 101, 5743-5748. [CrossRef]

20. Park, W.J.; Ahn, J.H. Effects of Microwave Pretreatment on Mesophilic Anaerobic Digestion for Mixture of Primary and Secondary Sludges Compared with Thermal Pretreatment. Environ. Eng. Res. 2011, 16, 103-109. [CrossRef]

21. Eskicioglu, C.; Terzian, N.; Kennedy, K.J.; Droste, R.L.; Hamoda, M. Athermal microwave effects for enhancing digestibility of waste activated sludge. Water Res. 2007, 41, 2457-2466. [CrossRef] [PubMed]

22. Byliński, H.; Aszyk, J.; Kubica, P.; Szopińska, M.; Fudala-Ksiazek, S.; Namieśnik, J. Differences between selected volatile aromatic compound concentrations in sludge samples in various steps of wastewater treatment plant operations. J. Environ. Manag. 2019, 249, 109426. [CrossRef]

23. Brancher, M.; Griffiths, K.D.; Franco, D.; de Melo Lisboa, H. A review of odour impact criteria in selected countries around the world. Chemosphere 2017, 168, 1531-1570. [CrossRef]

24. Nicell, J.A. Assessment and regulation of odour impacts. Atmos. Environ. 2009, 43, 196-206. [CrossRef]

25. Garlicka, A.; Zubrowska-Sudol, M.; Umiejewska, K.; Roubinek, O.; Palige, J.; Chmielewski, A.G. Effects of Thickened Excess Sludge Pre-Treatment Using Hydrodynamic Cavitation for Anaerobic Digestion. Energies 2020, 13, 2483. [CrossRef]

26. Angelidaki, I.; Alves, M.M.; Bolzonella, D.; Borzacconi, L.; Campos, J.L.; Guwy, A.J.; Kalyuzhnyi, S.; Jenicek, P.; van Lier, J.B. Defining the biomethane potential (BMP) of solid organic wastes and energy crops: A proposed protocol for batch assays. Water Sci. Technol. 2009, 59, 927-934. [CrossRef] [PubMed]

27. Rajput, A.A.; Zeshan; Hassan, M. Enhancing biogas production through co-digestion and thermal pretreatment of wheat straw and sunflower meal. Renew. Energy 2021, 168, 1-10. [CrossRef]

28. Montañés, R.; Solera, R.; Pérez, M. Anaerobic co-digestion of sewage sludge and sugar beet pulp lixiviation in batch reactors: Effect of temperature. Bioresour. Technol. 2015, 180, 177-184. [CrossRef] [PubMed]

29. Mata-Alvarez, J.; Dosta, J.; Romero-Güiza, M.; Fonoll, X.; Peces, M.; Astals, S. A critical review on anaerobic co-digestion achievements between 2010 and 2013. Renew. Sustain. Energy Rev. 2014, 36, 412-427. [CrossRef] 